\title{
Remuneração Variável: subjetivação e produção do professor-vendedor
}

Igor Vinicius Lima Valentim'

'Universidade Federal do Rio de Janeiro, Rio de Janeiro/RJ - Brasil

EVANGELISTA, Simone Torres. Remuneração Variável de Professores: produzindo um superador de metas. Rio de Janeiro: ComPassos Coletivos, 2013.

A remuneração variável em si não é uma novidade. A importação de políticas neoliberais para o setor público e até mesmo para a área da Educação no Brasil também não o são. Mas a equação se torna mais complexa e preocupante quando se criam políticas que unem remuneração variável como instrumento para gerir a educação e o trabalho de docentes em escolas públicas.

Simone Torres Evangelista nasceu e sempre residiu no Rio de Janeiro. Filha de pai motorista e de mãe artesã e costureira, sempre estudou na rede pública de ensino. Pedagoga pela Universidade do Estado do Rio de Janeiro, mestre e doutoranda em Educação pela Universidade Federal Fluminense, Simone trabalha há mais de quinze anos na Prefeitura da Cidade do Rio de Janeiro (PCRJ). Nos dois primeiros anos na Administração municipal, atuou como agente administrativo e, a partir de então, ocupou o cargo de professora, atuando como regente, coordenadora pedagógica, para além de cargos na gestão, tanto em Coordenadoria Regional de Educação (CRE) quanto na própria Secretaria Municipal de Educação (SME).

Educação \& Realidade, Porto Alegre, v. 40, n. 3, p. 955-961, jul./set. 2015. 955 http://dx.doi.org/10.1590/2175-623652261 
Remuneração Variável

O livro Remuneração Variável de Professores: produzindo um superador de metas mergulha no universo das políticas de gestão da educação pública do município do Rio de Janeiro, com especial atenção aos impactos trazidos pela adoção da remuneração variável como política de gestão do trabalho docente. O que sentem os professores e professoras? Como lidam com essa política? Como isso afeta o trabalho que realizam, seus cotidianos, saúde e vidas? Essas são algumas das fundamentais perguntas que esse livro busca aprofundar.

A obra tem como principal objetivo analisar os impactos - na produção de subjetividades - da adoção da remuneração variável por desempenho como parte da política de gestão da educação e do trabalho dos professores da rede municipal de educação do Rio de Janeiro.

Utilizando-se de uma abordagem conceitual apoiada em autores como Deleuze, Guattari e Foucault, a autora compreende a remuneração variável de professores da PCRJ como uma política de subjetivação, ou seja, de produção de subjetividades. Neste sentido, em um trabalho denso e coeso, analisa as legislações que regem o trabalho docente na rede carioca, lócus bem escolhido por adotar essa política desde a eleição do atual prefeito Eduardo Paes e da consequente nomeação de Claudia Costin como Secretária Municipal de Educação à época.

Para além do estudo documental, a autora vai a campo em prosseguimento à pesquisa teórica já publicada por Educação e Realidade (Evangelista; Valentim, 2013), vivendo períodos de observação participante e realizando diversas entrevistas com docentes da rede.

No capítulo um, Mudanças na Gestão do Trabalho Docente, Evangelista analisa diversas mudanças relacionadas à gestão do trabalho ao longo da história. A obra tem um mérito digno de reconhecimento e, muitas vezes, raro nos dias atuais: vai aos originais de Taylor e de Ford para mostrar a atualidade de suas proposições e políticas, apontando, por exemplo, que Taylor já propunha a remuneração variável como indutora de comportamentos desejados pelas empresas.

Passeando por teorias administrativas mais recentes como o Toyotismo proposto por Ohno, a autora bebe em Foucault e aponta que ainda que possa ser admitido que as relações laborais sejam um pouco menos coercitivas que no início do século vinte, isso ocorre porque se percebe que é mais lucrativo que o poder seja exercido de modo mais tênue sobre os corpos. Esse capítulo também aborda transformações do capitalismo e indica efeitos do neoliberalismo na gestão do trabalho no setor público, para além da análise de diversos aspectos trazidos pela emblemática Reforma Gerencial da Administração Pública Brasileira e o Plano Diretor da Reforma do Aparelho do Estado (PDRAE). A partir da racionalidade administrativa presente no PDRAE, o capítulo mostra diversas mudanças no cenário da educação pública brasileira, na autonomia docente e na avaliação da educação brasileira.

956 Educação \& Realidade, Porto Alegre, v. 40, n. 3, p. 955-961, jul./set. 2015. 
Dois aspectos levantados pela autora são centrais para o debate proposto pelo livro: o aumento da responsabilização e as mudanças na avaliação educacional brasileira. Com relação ao primeiro aspecto, a autora salienta que com a reforma educacional trazida pela LDB (Brasil, 1996) aumenta-se a responsabilização, "[...] que atribui o fracasso escolar à falta de competência da escola e de seus professores, desconsiderando que a ação educativa é afetada por problemas estruturais" (Evangelista, 2013, p. 47). Aponta ainda que "[...] mais que uma reforma gerencial, o que se viu foi um mecanismo de reformatar os papéis dos servidores públicos e suas subjetividades, assim como ocorreu com os trabalhadores de empresas privadas com o advento da reestruturação produtiva do capitalismo" (Evangelista, 2013, p. 49).

Já com relação ao segundo aspecto, é fulcral notar que a avaliação educacional passa a incluir a cultura da performatividade (Ball, 2005), utilizando julgamentos, comparações, exposições de resultados e indicadores como mecanismos de controle. A utilização de provas de avaliação em massa, com suas consequentes políticas contemporâneas no Brasil, não deixam dúvidas de que cada vez mais a avaliação passa a se basear em números, convertendo a vida em morte (Ferreira, 1996) ou, nas palavras da autora, "[...] o uso do IDEB promove uma quantificação do desempenho das diversas instituições de ensino público do país e também um ranking das mesmas, na medida em que faz com que cada uma passe a ter um índice como objetivo, um número como meta maior" (Evangelista, 2013, p. 49).

Por fim, o capítulo mostra que apesar da remuneração variável, como política de gestão da força de trabalho, já ser usada há dezenas de anos, a novidade está justamente quando essa política, oriunda da gestão de organizações privadas voltadas exclusivamente para o lucro, chega a ser utilizada para a gestão do trabalho docente nas instituições escolares públicas, feito que, na SME/RJ, teve início em 2009.

O capítulo dois olha para a prefeitura do RJ como organização. Passando rapidamente por um breve histórico, a análise da estrutura organizacional conduz os leitores a compreender um pouco mais a respeito de como a SME se insere dentro do governo. Traz informações relevantes a respeito da então secretária de Educação, responsável pela implantação da remuneração variável como política de gestão do trabalho docente. Essas informações apresentam especial interesse já que, na sequência, a autora analisa a política educacional da SME iniciada desde então, tentando caracterizar a nova política de remuneração docente da PCRJ como supostamente meritocrática.

É no capítulo três que Evangelista avalia profundamente o plano de cargos, carreira e remuneração dos professores da PCRJ, bem como as mudanças introduzidas juntamente com a remuneração variável. Aponta como as metas de desempenho vão sendo introduzidas para a rede municipal de educação, com base no IDEB de cada unidade esco- 
lar. Junto com a responsabilização, é introduzido o prêmio para aqueles professores lotados em unidades escolares que atinjam suas metas, ou melhor, as metas estabelecidas para eles pela Administração Municipal, de cima para baixo.

Ao descer mais um degrau na profundidade da investigação e olhar para as legislações pertinentes à implantação da remuneração variável para professores da PCRJ, é possível notar como a prefeitura do RJ não relaciona o prêmio apenas ao atingimento das metas relacionadas ao IDEB, mas também ao número de ausências dos professores durante o ano letivo.

Que mérito então essa política supostamente meritocrática aborda? Nas palavras da autora,

[...] toda a legislação que regulamenta a nova política de remuneração variável por desempenho se baseia em uma gestão do trabalho que bonifica pelo suposto mérito de elevar o desempenho escolar dos alunos, medido pelo alcance das metas do IDEB ou IDERIO por unidade escolar. Essa ideia consiste em atrelar desempenho escolar, controle do absenteísmo e estímulo financeiro, aplicando o método de eficiência de Taylor à administração de pessoal. Método que, teoricamente, está longe de preocupar-se com as necessidades humanas. Com esse método, o que a PCRJ pretende, com sua nova gestão, é uma reconfiguração dos papéis funcionais através de estímulos e sanções que moldam comportamentos, fazendo surgir novas subjetividades ao levar o docente tomar para si metas que são da SME/RJ (Evangelista, 2013, p. 87-88).

Na mesma linha de argumentação, a autora afirma, ainda, que

[...] [h]á uma tendência de julgar e responsabilizar os docentes por uma situação que, muitas vezes, lhes foge ao controle, já que seu desempenho é medido através dos resultados dos estudantes nas avaliações externas (Evangelista, 2013, p. 89, grifo da autora).

A parte mais rica da obra está compartilhada com os leitores no capítulo quatro. Nele, a autora relata a pesquisa de fôlego que fez com professores de pelo menos cinco escolas da rede municipal do Rio de Janeiro, com o intuito de investigar como a remuneração variável por desempenho da PCRJ impacta a vida dos docentes. A autora chegou a fotografar marcas de tiros nas paredes de uma escola, conversou com professores da rede a respeito da remuneração docente, do plano de carreira, da mudança na remuneração docente na PCRJ e, obviamente, da remuneração variável e seus impactos no cotidiano desses professores.

São numerosas as polêmicas trazidas pela embasada pesquisa da autora que, sem romper as fronteiras da ética e preservando as identidades dos participantes da investigação, traz diversos exemplos de como 
a política implantada estimula a venda da educação, tratada como mercadoria.

Foram vivenciadas situações nas quais foi percebida a atuação de professores doentes para não perderem o prêmio. Surgiram também, nos diálogos trazidos pela obra, questões relacionadas à perda da autonomia docente, à utilização de cadernos pedagógicos (apostilamento) e ao direcionamento da prática em função das avaliações em massa, via treinamento de alunos. Apareceram também condutas de professores que sugeriam a seus alunos que fizessem provas a lápis, entre outras. Não seria exagerado o entendimento de alguns que consideram que a utilização da manipulação de resultados para garantir um adicional ao salário fere a ética na educação, reduzindo-a a mera mercadoria e estimulando um utilitarismo que enterra o compromisso social da função docente. Mas o livro não traz o intuito de culpabilização. Muito pelo contrário. A análise é fiel ao seu quadro teórico-conceitual ao apontar a triste constatação de que esses comportamentos são estimulados na medida em que se implanta uma política como a analisada.

Talvez um dos mais tristes efeitos da obra seja constatar como a política de remuneração variável premia o entendimento do estudante como meio, e não mais como finalidade da educação. E isso não ocorre sem o sofrimento dos professores. Se de um lado fazem o que podem para tentarem assegurar uma parcela adicional em sua baixíssima remuneração, de outro sofrem ao controlarem os colegas, os estudantes e a se controlarem cada dia mais em prol de objetivos e metas das quais nem sequer participaram da construção. Nas palavras de uma das professoras participantes da investigação:

[...] eu acho que eu não tô sendo mais eu, eu professora. Eu fico muito ansiosa por querer um dinheiro a mais (Evangelista, 2013, p. 153).

Outro depoimento é ainda fundamental para ilustrar o argumento aqui analisado:

[...] eu me sinto assim muito angustiada, é uma coisa que eu não consigo me adaptar. Quer dizer, eu me adapto, mas eu não aceito. Não acho que prêmio é bacana (Evangelista, 2013, p. 153).

A pesquisa mostra casos de problemas na saúde de professores e até de desistência e de burnout (Codo, 1999). A temática do adoecimento docente não é nova, porém, cabe observar-se - em estudos futuros - em que medida vem se intensificando com a nova política, principalmente em um momento que o valor do professor, na visão da Administração Pública, parece estar cada vez mais reduzido a ser um permanente superador de metas.

Nas palavras de Deleuze, “[...] não cabe temer ou esperar, mas buscar novas armas” (Deleuze, 1992, p. 212). Não se pode mais esperar 
para quebrar com a naturalização de políticas e objetivos que foram estabelecidos por outras pessoas e organizações e que não potencializam a vida. É fundamental nos questionarmos mais a respeito das implicações daquilo que fazemos, muitas vezes sem nos dar conta, daquilo que concordamos, inclusive quando silenciamos.

Em um mundo dominado por mercados de compra e venda, os índices que medem a qualidade da educação também estão à venda. $\mathrm{E}$ custam cada vez menos aos cofres públicos, comprometendo cada vez mais o cotidiano de professores e estudantes e a própria qualidade da educação se esta for compreendida como ligada à formação de cidadãos críticos.

Não importam as condições de vida dos estudantes, nem as condições de trabalho nas escolas, nem tantas outras numerosas influências no desempenho de um estudante. Também não importa o tipo homogeneizante e conteudista de avaliação realizado. Os estudantes foram convertidos em meios para avaliar o trabalho docente, como se seus desempenhos dependessem única e exclusivamente dos trabalhos destes professores e professoras. E, igualmente grave, como se suas notas em avaliações em massa pudessem ser relacionadas apenas à qualidade da educação. Só importam os resultados obtidos pelos estudantes nas avaliações em massa. Essa é a qualidade naturalizada por todos sem ter sido sequer discutida.

Construímos cotidianos nos quais a pressa é cada vez maior e a reflexão pouco valorizada e até mesmo criticada. Este livro é leitura obrigatória não apenas para professores, mas para estudantes, pais e todos aqueles que desejam um entendimento da educação pública que estamos produzindo. Ele nos dá a oportunidade de refletir que não existem completos inocentes com relação ao sistema educacional contemporâneo. Embora a responsabilidade daqueles que elaboram políticas cruéis tais como aquelas aqui apresentadas seja inegável, cada atitude nossa, inclusive a de permanecer em silêncio ou de não questionar aquilo que (vi)vemos, ajuda a construir, ainda que pelo consenso ou pela passividade, o que nem sempre temos a coragem de criticar em nossas atitudes.

Obra corajosa, não só pelo tema, mas por escancarar os mecanismos utilizados para tentar contornar pressões, conseguir remunerações minimamente dignas - que nunca se tornam justas perante a responsabilidade que têm. Por ouvir os professores e construir sem medo o triste modus operandi da educação pública carioca em nível municipal hoje. Resistências e possibilidades? Submissão e complacência? Tudo parece desesperador quando se pensa na educação que se está construindo, bem como nos meios e políticas utilizados. Nos hábitos e subjetividades.

A pesquisa aponta o caráter doente e criador de doenças de nossa sociedade. Traça conexões entre políticas de gestão, subjetividade, ado- 
ecimento e culpa. São desnudadas as políticas de subjetivação em curso, ligadas à gestão do trabalho e da vida, como importantes elementos na construção de modos de ver, sentir, estar e trabalhar que conduzem grande parte das pessoas a enfermidades que não são apenas físicas, mas sociais, econômicas e, simultaneamente, existenciais.

Este livro é um contra-ataque em prol de subjetividades mais comprometidas com outros mundos e valores, diferentes daqueles hoje dominantes em nossas sociedades doentes, construídas por relações baseadas na repetição, na morte, na competição.

Não parece coincidência que os meses de agosto e setembro de 2013 testemunharam mais uma greve dos professores da municipal do Rio de Janeiro. E uma das reivindicações foi justamente relativa ao fim da remuneração variável. Entretanto, com um sistema judiciário de cegueira muitas vezes duvidosa, a greve foi declarada ilegal.

Por fim, espera-se que a obra possa servir como estímulo na direção de lutas, mobilizações e resistências em prol da produção de outras subjetividades e da construção de outras concepções de educação e de vida.

Recebido em 09 de dezembro de 2014 Aprovado em 09 de abril de 2015

\section{Referências}

BALL, Stephen. Profissionalismo, Gerencialismo e Performatividade. Cadernos de Pesquisa, São Paulo, Fundação Carlos Chagas, v. 35, n. 126, p. 539-564, set./ dez. 2005

BRASIL. LDB. Lei 9394/96. Lei de Diretrizes e Bases da Educação Nacional. Diário Oficial da União, Brasília, 23 dez. 1996. P. 27833. Disponível em: <http:// www.planalto.gov.br/ccivil_03/Leis/L9394.htm>. Acesso em: 20 set. 2014.

CODO, Wanderley (Coord.). Educação: carinho e trabalho. Petrópolis: Vozes, 1999.

DELEUZE, Gilles. Conversações (1972-1990). Rio de Janeiro: Editora 34, 1992.

EVANGELISTA, Simone Torres. Remuneração Variável de Professores: produzindo um superador de metas. Rio de Janeiro: ComPassos Coletivos, 2013.

EVANGELISTA, Simone Torres; VALENTIM, Igor Vinicius Lima. Remuneração variável de professores: controle, culpa e subjetivação. Educação \& Realidade, Porto Alegre, v. 38, n. 3, p. 999-1018, jul./set. 2013.

FERREIRA, José Maria Carvalho. Pedagogia Libertária Versus Pedagogia Autoritária. 1996. Disponível em: <http://www.cedap.assis.unesp.br/cantolibertario/textos/0139.html>. Acesso em: 20 set. 2014.

Igor Vinicius Lima Valentim é professor da Faculdade de Educação da Universidade Federal do Rio de Janeiro.

E-mail: valentim@gmail.com 